\title{
Uma questão política: a exclusão dos lentes dominicanos das cátedras universitárias de Coimbra*
}

FERNANDO TAVEIRA DA FONSECA

Faculdade de Letras da Universidade de Coimbra

1. No contexto da história da universidade portuguesa, a faculdade de Teologia teve um estatuto singular que a distinguiu das restantes faculdades maiores. Uma tese tradicionalmente aceite foi a de que ela não faria parte do elenco fundacional dos cursos universitários, de acordo com o que se praticou na maioria dos estudos criados até finais do século XIV, ou por carência de meios, nomeadamente de mestres competentes, ou, na leitura de Mário Brandão, como consequência de uma política pontifícia que restringia a proliferação das faculdades de Teologia, para realçar a importância da universidade de Paris, verdadeiro "romanae sedis studium". Não deixa, porém, este autor de assinalar

Ao dedicar este trabalho aos Professores Luís Ferrand de Almeida e António de Oliveira, Mestres que constituem para mim referências primeiras da vida universitária, pela sua grande humanidade e profundo saber, não posso deixar de assinalar que, na sequência de tantos benefícios que de um e outro recebi, também alguns dos documentos que aqui utilizo (os provenientes da Biblioteca da Ajuda) me foram facultados pelo Professor António de Oliveira.

Mário Brandão e Manuel Lopes de Almeida, A universidade de Coimbra. Esboço da sua história, Coimbra, 1937, $1^{\star 2}$ parte, pp. 28-31. Mário Brandão cita Denifle para afirmar que "dos 48 estudos gerais que surgiram até final do século XIV, 28 foram fundados sem faculdade de teologia" (p. 30). 
que cabia às ordens de $\mathrm{S}$. Francisco e de S. Domingos a primazia dos estudos teológicos que se professavam em escolas episcopais e monacais, acrescentando que terá sido precisamente a franciscanos e dominicanos que D. Dinis "parece ter deixado o cuidado do ensino da teologia nas suas escolas privativas", sendo "absolutamente seguro, que depois de transferir a Universidade para Coimbra em 1308, determinou que a teologia aqui fosse professada nos conventos de S. Domingos e S. Francisco".

A recente interpretação de José Antunes, afirmando a existência efectiva de uma faculdade de Teologia na universidade portuguesa desde os seus primórdios ${ }^{3}$, coincide num ponto - o que aqui mais nos interessa - com a tese anteriormente exposta: que a franciscanos e dominicanos foi oficialmente confiado o encargo de, nos seus conventos, professarem o estudo e o ensino da sacra pagina. Esta determinação, inserta na Carta Magna de Privilégios (15 de Fevereiro de 1309), outorgada por D. Dinis logo após a primeira transferência da universidade para Coimbra (1308), revela a importância das duas ordens mendicantes uma e outra ilustradas por luminares de primeira grandeza - no cultivo da Teologia, com o consequente exercício da sua docência ao mais alto nível.

Esta longa tradição ajudará a compreender o que acima afirmávamos acerca da especificidade da faculdade de Teologia, que se mantém depois da implantação definitiva da universidade em Coimbra, em 1537: a sua realidade formal, ministrando um ensino regular e concedendo, sem qualquer restrição, os respectivos graus, compaginava-se com a existência de outras instituições, exercendo idênticas ou paralelas funções docentes. Falamos, como é evidente, dos numerosos colégios pertencentes a diversas ordens religiosas e militares, que se foram progressivamente implantando na cidade e incorporando na universidade ${ }^{4}$. Albergando estudantes, opositores às cátedras universitárias e os próprios professores da faculdade de Teologia - importa salientar que entre 1537 e $1771,77 \%$ dos lentes teólogos pertenceram a diversas famílias religiosas

Ibidem, p. 32.

José Antunes, "A Teologia", in História da Universidade em Portugal, Coimbra-Lisboa, 1977, vol. I, tomo I, pp. 237-249.

Para a cronologia da implantação dos colégios universitários veja-se António de Vasconcelos, "Os colégios universitários de Coimbra (fundados de 1539 a 1779)", Escritos vários, (reed.) vol. I, Coimbra, 1987, pp. 155-295; e, em termos de impacto na configuração da cidade, Ana Paula Margarido e Margarida Vilar Queirós, "A universidade de Coimbra e as alterações na malha urbana da Alta", in Universidade(s). História, Memória, Perspectivas, Coimbra, 1991. vol. 2, pp. 357-394. 
ou às ordens militares - eram também sede de uma docência regular que habilitava muitos dos seus membros para a incorporação formal na universidade (mediante simples acto administrativo), numa fase já adiantada do seu percurso académico, muito próxima da obtenção das graduações últimas de licenciado e doutor ${ }^{5}$. O panorama que podemos observar em 1717, aquando do juramento da bula Unigenitus - apuseram a sua assinatura ao documento então elaborado 75 religiosos de diversos colégios, todos eles intitulando-se lentes de Teologia será, sem dúvida, o resultado de uma evolução e o espelho de uma realidade que, pelo que vimos, pode, com segurança, ser projectada retrospectivamente.

2. Neste contexto de alguma singularidade da faculdade de Teologia, mais singular ainda era a posição dos dominicanos. Como é sobejamente conhecido, os anos que se seguiram à transferência de 1537 ficaram marcados, nesta faculdade como nas demais, por um esforço de fixação normativa, de ampliação do elenco curricular e de consolidação do corpo docente universitário. Desempenhou então papel decisivo a acção pessoal de D. João III, sobretudo através do convite endereçado a professores, muitos dos quais, havendo alcançado merecida notoriedade em universidades estrangeiras, ascenderam às cátedras conimbricenses sem passarem pela formalidade dos concursos ${ }^{6}$. À medida, porém, que o corpo de normas se ia consolidando (podendo nós assinalar como datas marcantes os anos de 1544 e de $1559^{7}$ ), os procedimentos formais no acesso às cadeiras ${ }^{8}$ foram ganhando maior relevo, sem que de todo

Tratei mais amplamente desta temática em A universidade de Coimbra (1700-1771). Estudo social e económico, Coimbra, 1995, pp. 241 -245; e em "A Teologia", in História da Universidade em Portugal, Coimbra-Lisboa, 1977, vol. I, tomo II, pp. 782-787. A incorporação formal, sem necessidade da prestação de quaisquer provas académicas, atesta do reconhecimento que a universidade concedia aos estudos feitos nos colégios nela incorporados.

Para uma panorâmica sobre esta temática, veja-se, por todos, Sebastião Tavares de Pinho, "A mobilidade dos universitários", in História da Universidade em Portugal, Coimbra-Lisboa, 1977, vol. I, tomo II, pp. 991-1014, sobretudo, pp. 991-1003.

$\mathrm{Na}$ primeira destas datas terão sido promulgados novos estatutos para a universidade, cujo texto nos é hoje desconhecido. De 1559 são os Estatutos da Universidade de Coimbra não há muito encontrados por Serafim Leite e publicados em 1963 (Coimbra, Por Ordem da Universidade). Embora promulgados dois anos depois da morte do Piedoso, é legítimo ver neles a primeira sistematização que se conhece resultante de todo o processo da reformajoanina da universidade.

Que eram o concurso, implicando um conjunto de provas públicas e uma votação (na qual. até 1654, intervinham, de direito, os estudantes) ou o chamado "ascenso", pelo qual, vagando uma das cadeiras, o professor da imediatamente inferior a ocupava, sendo os que se lhe seguiam deslocados também um lugar para cima (vide Fernando Taveira da Fonseca, A universidade de Coimbra (1700-1771), pp. 448-469). 
tenha cessado a intervenção directa do monarca, de que há numerosos exemplos: o mais notável terá sido o do convite endereçado ao jesuíta Francisco Suárez, o qual efectivamente ocupou a cátedra de Prima de Teologia entre 1597 e $1616^{\circ}$.

A referência a Suárez justifica-se porque a sua nomeação excepcional ${ }^{10}$ para a cadeira mais eminente da faculdade de Teologia veio interromper a série de outras duas nomeações - perfazendo, contudo, cerca de quarenta anos de posse - de lentes dominicanos, para essa mesma cátedra, também elas de carácter peculiar. A memória destas nomeações manteve-se e foi invocada muito mais tarde, num contexto de que adiante trataremos. Servir-nos-emos dela aqui, apenas para indicar que aos dominicanos fora concedido um estatuto privilegiado: transitavam directamente dos estudos da sua religião para as posições cimeiras do professorado da faculdade de Teologia, sem que haja notícia de alguma vez se terem submetido a concurso ou ao normal percurso ascendente que, para a generalidade dos lentes, principiava nas cadeiras demenor graduação ${ }^{11}$.

Sobre o percurso de Francisco Suárez na universidade de Coimbra, veja-se o importante estudo de António de Vasconcelos, "Dr. Francisco Suárez, doctor eximius" in Estudos vários, vol. II, Coimbra, 1941, pp. 161-486, com abundante documentação.

Na carta de nomeação, endereçada ao Reitor e aos lentes, deputados e conselheiros da universidade de Coimbra, o monarca ordena que Suárez seja admitido a ler a cadeira de Prima "sem embargo de elle não ter graõs nessa Universidade, nem em outra" (Vasconcelos, "Dr. Francisco Suárez", p. 311). Suárez obterá, ainda em 1597, o grau de doutor das mãos do seu Provincial - no exercício de um privilégio pontifício que lhe concedia essa prerrogativa - mas, mesmo assim, para obviar a algumas críticas, fez actos públicos em Évora e recebeu, em 4 de Junho de 1597, "com o cerimonial do estilo, o grau de doutor". Em Outubro desse ano pediu a sua incorporação como doutor em Coimbra a qual "lhe foi concedida em conformidade com os estatutos" (ibidem, pp. 196-197 e documento VI, p. 317).

"Este estatuto especial é afirmado explicitamente no momento em que, na eminência de se verem privados das cátedras universitárias, os dominicanos apresentam as suas razões a D. João IV. Na réplica a essa representação, elaborada por um franciscano, afirma-se que, para todos os lentes "o direito que acquiriram em levar a cadeira levava inclusa esta obrigação de guardar as Leys"; e acrescenta: "e sendo isto em todos os lentes, he mais evidente nos que levão as cadeiras não por opposição senão por mera graça de V. Magestade"; na tréplica, Fr. Domingos do Rosário responde: "que isto que quer improperar à ordem de $\mathrm{S}$. Dominos por mengua he huma das suas grandezas, que os Principes fião tanto de sua sufficiencia que sem opposição nem examen concedem suas cadeiras..." (Biblioteca da Ajuda-B.A. -, 50-V-32. Sob esta cota encontram-se três documentos: uma representação endereçada a D. João IV por Frei Domingos do Rosário , fls. 470-473 (doc. 1); uma réplica elaborada por um autor franciscano, fls. 474-478v. (doc. 2), e uma longa resposta a esta réplica, pelo autor do primeiro "papel", fls. 450-464 (doe. 3). Nenhum destes "papéis" está datado mas é indubitável que terão de sê-lo entre 1646 e 1648. Foram-me estes documentos cedidos pelo Prof. Doutor António de Oliveira, a quem, mais uma vez, agradeço As citações foram, colhidas nos doc.s 2 e 3). 
O primeiro desses religiosos a ocupar a cátedra de Prima fora Frei Martinho de Ledesma: começara em 1540 por ler Escritura, transitando logo no ano seguinte para Véspera e ascendendo a Prima, em 1557, por jubilação de Afonso do Prado ${ }^{12}$. Sucedeu-lhe no lugar Frei António de S. Domingos (começou a reger em 13 Outubro de $1574^{13}$ ), chamado originalmente para seu substituto (26 de Outubro de 1573), por tempo indeterminado. A provisão que o nomeia é bem o testemunho do carácter excepcional do seu provimento: ficava, na sua qualidade de substituto, a gozar de imediato de todas as prerrogativas de lente proprietário da cadeira, assim como de todas as honras, preeminências e liberdades como se fora doutor por Coimbra "posto que o nõ seja senão pela sua ordem"14. Por mandado régio, prestava assim a universidade o seu reconhecimento a graduações concedidas internamente nos estudos dominicanos, equiparando-as mesmo ao grau de doutor que só ela conferia: a incorporação de Frei António nesse grau de doutor, que viria a processar-se em 1574, não foi mais que o cumprimento de uma formalidade administrativa.

Jubilou em 1593, debilitado na sua saúde. O processo de provimento da vacatura que se abria com o seu afastamento da docência veio, finalmente, a dar origem à nomeação de Francisco Suárez, não sem que, antes disso, Frei António de S. Domingos tivesse sido reconduzido (Abril de 1595); mas, durante a maior parte do tempo que decorreu entre 1593 e 1597, a docência da cadeira de Prima foi assegurada por substitutos. O falecimento de Frei António (entre 15 e 21 de Junho de $1596^{15}$ ) veio acelerar o processo de nomeação de Suárez que inicialmente recusara a incumbência.

Francisco Leitão Ferreira, Alphabeto dos lentes da insigne universidade de Coimbra, Coimbra, 1937, p. 254. Afonso do Prado fora lente de Prima desde a primeira hora da transferência para Coimbra, tendo começado a ler a 2 de Maio de 1537 (ibidem, p. 3).

Ibidem, p. 10; A. Xavier Monteiro, Frei António de São Domingos e o seu pensamento teológico (sobe o pecado original), Coimbra, 1952, p. 40.

A. Xavier Monteiro, Frei António de São Domingos, p. 40. Será importante referir que, embora os lentes pudessem não ter o grau de doutor, este se tornava necessário para o exercício de actos públicos (apadrinhar e presidir), onde as questões de precedência tinham um peso acentuado. Além disso (ou talvez por isso mesmo), os Estatutos de 1597 (liv. III, tít. VII) determinavam que todos aqueles que ocupassem cadeiras como bacharéis ou licenciados teriam prazos definidos para obter o grau de doutor. E se esta exigência se colocava para o conjunto das cadeiras, muito mais se justificava para a de Prima.

Ibidem, p. 122. 
Não cabe aqui demorarmo-nos nesta transição ${ }^{16}$ : referiremos apenas que com ou sem fundamento, se gerara nos dominicanos a convicção, de que a cátedra de Prima de Coimbra havia sido concedida não apenas aos professores dominicanos que a haviam regido, mas à própria Ordem, como o declara expressamente Frei Pedro Monteiro no Claustro Dominicano: "Felipe II de Castela, ignorando estar a cadeyra de Prima dada de propriedade à religião de S. Domingos a proveo na pessoa de Francisco Soares, da Companhia de Jesus"' Uma das primeiras reservas que, seguramente, Suárez e o Visitador Geral, o Padre Garcia de Alarcón, haviam colocado à aceitação, por parte do jesuíta, da regência para que o convidavam, era a eventualidade de gerar-se, por isso, algum confronto com os dominicanos. O monarca tranquiliza o Visitador: "y puesto que me apuntais sobre los religiosos de Santo Domingo, no ay inconveniente alguno, por ellos no tener derecho en la dicha Cathedra: la cual se acostumbra proveer, ò por oposición, ò por mi mandado, y que ya la hubieron otras personas, sin ser religiosos de la dicha Orden, ni huviesse hasta ahora en aquel Reyno entre la Compañía, y la dicha Orden, diferencia alguna: yo mandaré proveer en esto de manera, que se evite toda la ocasión de poderla aver en lo adelante." ${ }^{18}$

Interessa reter esta denegação formal do direito dos dominicanos à propriedade da cadeira de Prima ("por ellos no tener derecho en la dicha Cathedra"). A verdade, porém é que, terminado o percurso de Suárez em Coimbra, pela jubilação ocorrida em 13 de Frevereiro de 1616, é nela empossado, de novo, um dominicano, Frei Vicente Pereira, por força de uma provisão de 10 de Dezembro do mesmo ano. ${ }^{19}$ E sendo ele ainda proprietário dela - é legítimo

A. Xavier Monteiro, na obra que vimos referindo, dedica-lhe algumas páginas, nas quais, face à documentação que aduz, diverge, em alguns aspectos, da narrativa de António de Vasconcelos, também já atrás citada. Importa pôr de relevo o que aquele primeiro autor refere acerca de uma consulta da Mesa da Consciência e Ordens na qual se propõe que a leccionação de Prima, após a jubilação de Frei António de S. Domingos, seja assegurada por substituição, indigitando para o efeito o nome de Frei João de Valadares, ao tempo prior do mosteiro de S. Domingos em Lisboa "por ler muitas vezes na Ordem e ser religioso grave, muito douto e estudioso" (p. 114). Neste caso, mantinha-se a linha de continuidade, assegurando a sucessão dominicana ao lente jubilado de Prima.

Citado por A. Xavier Monteiro, Frei António de S. Domingos, p. 117.

${ }^{18}$ Documento em António de Vasconcelos, "Dr. Francisco Suárez", p. 184.

${ }^{19}$ Francisco Leitão Ferreira, Alphabeto dos Lentes, p. 256. Na informação que. a pedido da Mesa da Consciência e Ordens o então Reitor, Manuel de Moura Manuel, envia àquele tribuna , em 14 de Janeiro de 1686, afirma ele que a Frei António de S. Domingos terá imediatamente sucedido Frei Vicente Pereira, ("ainda que se não acha Provisão desta mercê com tudo he couza indubitavel que a houve pelo que abaxo se declara"). A convicção do Reitor advém-lhe do facto de ser conhecida a nomeação de Frei António da Ressurreição, em 1620, na qual se declara que 
supor que por cuidado dos dominicanos, para que se não vissem de novo privados desse que julgavam ser o seu direito - um alvará de 8 de Setembro de 1620 concede a substituição e futura sucessão a um outro dos Pregadores, Frei António da Ressurreição. Será interessante atentar nos precisos termos da concessão régia: "hey por bem e me praz de fazer merce ao dito Padre, digo ao dito Mestre Frey Antonio da Ressurreição de o prover na substituição da dita Cadeira de Prima de Theologia com a futura susesão delia pera quando vagar pello dito Doutor Frey Vicente Pereira [...] e que ao dito Mestre Frey Antonio da Ressurreição se dará logo o grau de doutor, e previlegios de lente pera poder padrinhar e presidir nos actos publicos assi e da maneira que o fazem os mais lentes"20.

Repete-se o procedimento que fora utilizado para Frei António de S. Domingos. Mais importante, contudo, é a declaração, expressa no mesmo alvará, de que a cadeira havia sido outorgada aos dominicanos. Textualmente: "e por confiar delle que lerá com satisfação a Cadeira de Prima de Theologia dessa Universidade que se deu à dita Ordem..." (itálico nosso). Idêntica declaração é repetida na provisão, de 23 de Fevereiro de 1635, que nomeia Frei André de Santo Tomás para ocupar a vaga deixada por Frei António da Ressurreição,

ele sucede a Frei Vicente Pereira, que então era o proprietário: "na qual Provizão se declara ser então actualmente proprietario delia o dito Fr. Vicente Pereira donde, como assima fica advertido se deixa bem ver que o proprio Fr. Vicente Pereira succedeu na deira (sic) de prima ao dito fr. Antonio de São Domingos e que iuntamente era proprietario nella com o Padre Francisco Soares" (Mesa da Consciência e Ordens(MCO), Universidade de Coimbra(UC), maço 60). O Reitor estabelece assim uma linha ininterrupta de sucessão, até à exclusão de Fr. Diogo Artur nas circunstâncias que adiante relataremos, o que lhe permite formular o parecer de que a cadeira de Prima deveria ser restituída aos dominicanos, submetendo-se eles ao juramento da Conceição. Mas não tem conhecimento da provisão referida por Leitão Ferreira. A informação de que Frei Vicente Pereira fora provido apenas em 1616 consta igualmente de uma certidão passada em Madrid, no ano de 1693 (20 de Abril), por Dom Crispim Gonzalez Botello "del Consejo de Su Magestad y su Secretario de Estado delia negociacion del Norte, en cuyo poder paran los papeies y consultas de la Secretaria del Consejo de Portugal que residia en esta Corte [Madrid]". Atesta ele que entre esses "papelles y consultas" havia um decreto pelo qual Filipe III "hasia mercede a la religion de Santo Domingo que se probeyese en religioso de ella la cátedra de prima de Theologia de la Universidad de Coimbra para quando bacase por la jubilacion del Doctor Francisco Suarez [...] y por resolucion à consulta del Consejo de Portugal de veinte y três de Octubre del dicho anno de seis cientos y quinze se servio Su Magestad nombrar para la dicha catedra de Prima al Maestro Fray Visente Pereira de la misma hordem de Santo Domingo por haverse jubilado en ella el dicto Doctor Francisco Suarez de que se abizo al virrey de Portugal conforme al estilo por carta de Su Magestad de tres de Octubre de mil seis cientos e diez y seis" (MCO, $U C$, maço 60).

\section{Ibidem.}


entretanto promovido ao bispado de Angra ${ }^{21}$. Frei André, diz-nos Manuel de Moura Manuel na já citada informação elaborada em 14 de Janeiro de 1686 por mandado da Mesa da Consciência Ordens, "não era tambem lente ao tempo do provimento, e leu a dita cadeira athe o mes de Julho do anno de 1639 no qual faleceu...". Mas deixemos o Reitor prosseguir a sua narrativa retomando-a no exacto ponto onde a deixámos:

"... e lhe succedeu por provizão do dito Rej de 30 do mes de Julho da dita era de 1639 o Padre mestre Fr. Diogo Artur outrosi religioso Dominico o qual tambem naõ era doutor nem lente [riscado: e continuou a leitura da dita cadeira de prima] e se encorporou e fez depois Doutor, por Provisão do dito Rej e continuou a leitura da dita cadeira de Prima athe o anno de 1649, no qual tempo a Magestade do Senhor Rej Dom João o quarto da (sic) saudosa memoria mandou haver por vaga a dita cadeira de Prima, por iustas cauzas, que dis que para isso teve em huma carta escrita ao Reitor e Claustro desta Universidade em 29 dias do mes de Março do dito anno e ainda que não declara as ditas causas he couza notoria, que por não querer o dito Padre Frei Diogo Artur, fazer o iuramento solemne da Conceição da Virgem Senhora Nossa que o mesmo Senhor Rej no anno de 1646 tinha mandado que perpetuamente se fizesse nesta Universidade por todos os lentes e graduados delia; foi removido da regencia da dita cadeira o sobredito Padre Fr. Diogo Artur e foi o dito Senhor Rej servido provella em o Padre Doutor Fr. Leão de Santo Thomas, religioso de São Bento que então era lente de Vespora de Theologia e daquelle tempo athe o prezente forão sempre providos na dita cadeira de prima homens Doutores que se achavão lentes de vespora no tempo da sua vacatura."

Haverá alguma imprecisão neste relato do Reitor. De facto, a provisão que nomeia Fr. Leão de Santo Tomás data-a Leitão Ferreira de 29 de Março de 1648 (com posse a 11 de Abril do mesmo ano), coincidindo assim o Reitor no dia e no mês, mas divergindo no ano ${ }^{23}$. Retenhamos, contudo, o essencial: que

Ambos os alvarás aqui citados constam de um traslado solicitado pelos dominicanos, o qual inclui também a certidão passada por Dom Crispim Gonzalez Botello, atrás referida. Torna-se evidente que o que eles pretendiam era apresentar, como argumento a seu favor, as provisões onde se declarava que a cadeira havia sido entregue à Ordem dos Pregadores. É provavelmente por isso que outras nomeações, como a de Frei Diogo Artur, não são incluídas nesta cópia.

MCO, UC, maço 60

Francisco Leitão Ferreira, Alphabeto dos lentes, pp. 41-42. É também a partir de Leitão Ferrreira que se pode matizar a afirmação do Reitor de que Fr. Diogo Artur "naõ era doutor nem lente": na realidade ele fora "Lente de Prima do Collegio de Santo Thomas de Avila, que he Universidade aprovada ainda que não geral" (p. 19); mas é certo que não era doutor por Coimbra nem fizera carreira aqui. Acerca do ano da nomeação e posse de Frei Leão de Santo Tomás não há dúvida que foi o de 1648 . 
Frei Diogo Artur fora privado da propriedade da cadeira de Prima de Teologia, por não se submeter à determinação de D. João IV que obrigava professores e graduados por Coimbra a jurarem solenemente a Conceição Imaculada da Virgem Maria; que, desde então, a cadeira de Prima havia sido assegurada por lentes de "carreira", pertencentes a outras famílias religiosas que não os dominicanos; que estes últimos procuravam reaver a sua posição na universidade (era esse precisamente o motivo de se ter pedido ao Reitor a sua informação e o seu parecer).

3. Era antiga a controvérsia que opunha as escolas teológicas franciscana e dominicana acerca da Conceição: na esteira de Duns Escoto, aquela defendia a chamada pia opinio, a de que a Virgem Maria fora isenta do pecado original desde o primeiro instante da sua concepção; afirmando seguir Santo Tomás de Aquino, os dominicanos não aceitavam essa proposição por ela implicar, no seu entender, que a redenção de Cristo não poderia então considerar-se universal. ${ }^{24}$ A controvérsia teológica era já de si susceptível de provocar conflitos, tanto mais que não havia uma definição explícita da autoridade eclesiástica que dirimisse a questão (a proclamação dogmática da Imaculada Conceição virá a ter lugar apenas a 8 de Dezembro de 1854), limitando-se esta

${ }^{24}$ Não cabe aqui demorarmo-nos sobre esta questão: anotarei apenas a formulação tomista, expressa na questão XXVII da terceira parte da Summa Theologica (De beatae Virginis Mariae sanctificatione) que, não sendo a única do Doutor Angélico é a mais conhecida. Partindo da distinção entre o momento da concepção e o da animação (infusão da alma no feto) e respondendo à questão "Utrum beata Virgo fuerit sanctificata ante animationem", conclui: "cum beata Virgo redemptione et salute quae per Christum est indiguerit, non nisi post animationem sanctificata fuit" (Summa Theologica S. Thomae Aquinatis, Lugduni, sumptibus Andreae Laurens, 1747, $3^{a}$ p., q. XXVII, art. $2^{\circ}$ ). Para Tomás de Aquino o ser humano só é racional depois de receber a infusão da alma, e só como ser racional é sujeito de pecado e da consequente e necessária redenção que vem por meio de Cristo" (quae per Christum est): daí que conclua que Maria só foi santificada como ser racional, ainda no ventre materno mas não desde o momento da sua concepção. A opinião contrária pode ser sintetizada na formulação de S. Tomás de Vilanova, citada por Fr. Egídio da Apresentação: "Non decebat sanctuarium Dei aliquam in se labem habere, propter quod antequam animam illam sanctissimam infunderetur, plene fuit caro illa mundata ab omni faece et labe, et anima, cum infusa est, nullam habuit ex carne, neque contraxit labem peccati" (De Immaculata Beatae Virginis Conceptione ab omni peccato originali immune libri quatuor, authore Fr. Aegidio de Praesentatione, Conimbricae, apud Didacum Gomez de Loureyro, 1617). Uma e outra destas formulações têm como base a ideia corrente de que a animação do feto ocorria num determinado momento da gestação, posterior ao da concepção. O manual de confessores de Martim de Azpilcueta formula-a deste modo: "E ho menino começa a ter alma aos corenta dias, se he macho, e aos oytenta, se he femea, segundo huma glosa recebida" (Martim de Azpilcueta, Manual de confessores epenitentes, Coimbra, 1560, cap. XV, ${ }^{\circ} 14$, p. 145). 
a determinar que nenhuma das proposições opostas poderia ser considerada herética e a pôr limites à discussão pública para que não degenerasse em escândalo; para além, contudo, da divergência teórica era necessário contar com a grande difusão do culto da Imaculada Conceição, também a nível oficial com a celebração litúrgica a 8 de Dezembro, e com a adesão popular, assim como de autoridades, de comunidades e de universidades, que fora engrossando desde tempos medievais, implicando um enorme investimento afectivo e emotivo potenciador de uma conflitualidade que em alguns momentos chegou mesmo a eclodir.

De um desses momentos nos dá conta o beneditino Frei Egídio da Apresentação, professor conimbricense, no seu De Immaculata Beatae Virginis Conceptione $^{25}$ : ao dedicá-lo ao monarca, Filipe III, afirma tê-lo redigido e editado sob os seus auspícios e por ordem sua, passada "aquela tormenta que nos últimos anos tinha sacudido quase toda a Hispânia", que em mais de um lugar levara ao derramamento de sangue, e cujas ondas alterosas o rei pacificara $^{26}$; e, louvando a sua piedade, refere a constituição da Real Junta da Imaculada Conceição, tribunal particular destinado a examinar os problemas que sobre esta matéria se levantassem ${ }^{27}$, e as diligências feitas junto do papa para que definisse explicitamente doutrina, de modo a sustar definitivamente toda a controvérsia ${ }^{28}$.

Foi neste contexto que o rei solicitou às universidades da península que reforçassem esta pretensão. A carta que escreveu para Coimbra ${ }^{29}$, foi lida e examinada em Claustro Pleno de 9 de Dezembro de 1617. Atentamente notou António de Vasconcelos que a acta desta reunião revela uma viragem na decisão

Citado na nota anterior.

${ }_{26}$ "Prodit ille [...] aperto iam coelo, et pacatis Euris post turbidam illam procellam, quae proximis annis totam ferme Hispaniam concitauit; cuius tumentes fluctus pie, leniterque, sedasti" (fl. 3).

António de Vasconcelos, O mystério da Immaculada Conceição e a Universidade de Coimbra, Coimbra, 1904, p. 29.

Ibidem,p. 75, nota 37.

29 Transcrita no assento do Claustro Pleno de 9 de Dezembro de 1617, publicado por António de Vasconcelos, O mystério da Immaculada Conceição, p. 76, nota 39. Nela o monarca, dirigindo-se ao Reitor, lentes, deputados e conselheiros da Universidade, declara-lhes: "Ja deveis ter entendido quão affectuosamente desejo que o Santo padre declare o mesterio da purissima Concepção da vergem nosa Senhora [...] todavia entendendo que sera muito importante para mover o animo de Sua Santidade que em particular se lhe senefique por outras uias: uos encomendo e encarrego muito que por uossa parte manifesteis a Sua Santidade o que aserca deso sentis ou sente essa universidade; e a consolação que vniuersalmente causara uello deffinido, pedindo que o mande resoluer com breuidade [...]." 
tomada: resolvera-se primeiro escrever de imediato ao monarca, agradecendo a confiança, e ao papa "na conformidade que Sua Magestade manda"; mas decidiu-se, afinal, convocar uma junta de lentes ("todos os lentes theologos e os lentes de canones e prima e uespera das outras faculdades") que iria definir os termos da exposição ao papa. Adianta Vasconcelos que a presença de um dominicano nesta reunião do Claustro Pleno (Frei João Aranha, então lente de Escritura) terá estado na origem desta inflexão, anotando ainda que a não inclusão do lente de Prima, o também dominicano Frei Vicente Pereira, na comissão encarregada de redigir as missivas revela o cuidado em não ferir os "melindres de escola."

A junta de lentes reuniu-se uma semana depois, elaborando um texto cauteloso: "que a opinião que esta vniversidade sempre teve depois que he fundada he que a uirgem nosa Senhora não teue pecado original, e que esta defendeo sempre e leo nella e que isto mesmo sentião todos os doutores presentes em particular". Era possível emitir-se uma declaração deste teor - mesmo escondendo parte da realidade - numa faculdade de Teologia que incluía uma cadeira de Escoto; e não se faltava à verdade quanto ao sentimento de "todos os doutores presentes", uma vez que Frei Vicente Pereira e Frei João Aranha, como explicitamente nota o secretário, "não vierão a esta junta."

Este episódio parece não ter tido outros desenvolvimentos. Mas o problema voltará a colocar-se, agora com maior acuidade, depois da elevação ao trono do Duque de Bragança. E a frente do conflito alarga-se pela interferência activa dos franciscanos. A narrativa dos acontecimentos está elegantemente feita por António de Vasconcelos ${ }^{31}$, pelo que aqui apenas assinalaremos alguns aspectos que nos parecem mais pertinentes.

Foi efectivamente através de uma petição do provincial dos franciscanos que a questão foi posta na reunião do Claustro de 9 de Junho de 1645. Haviam-se aqueles empenhado, como narra Fr. Fernando da Soledade para "que nos Synodos dos bispados de Portugal, e na Universidade de Coimbra" se fizesse juramento de "defender a Conceyçaõ da Mãy de Deus", diligenciandojunto de

Io Ibidem, pp. 77-78, nota 40. Não viera também o Doutor João Bravo Chamiço, lente de Véspera de Medicina. O secretário acrescenta, justificando que fora impossível juntar todos os convocados: "o goarda deu sua fe de como os chamou, e o padre fr. Vicente Pereira por estar doente não podia uir e os mais não uierão tendo recado E asi se procedeu com ajunta sem elles as noue oras que comesou estando dado recado para as outo".

No trabalho que temos vindo a citar e também em "A doutrina da Immaculada Conceição e a Universidade de Coimbra", O Instituto, n XL1, 1993-94, pp. 1073-1105. Ambos os trabalhos são ricos de abundante documentação, que aqui aproveitámos largamente, cotejando-a contudo. com os originais existentes no Arquivo da Universidade de Coimbra (A.U.C.). 
D. João IV para que "ordenasse à Universidade de Coimbra não desse grao a sugeyto algum sem o tal juramento. ${ }^{132}$ Não fazendo eles próprios parte do corpo professoral $^{33}$, tinham conseguido que a sua petição fosse também assinada por diversos lentes (não sabemos exactamente quantos).

O problema mudara substancialmente: tratava-se não de defender uma doutrina ou de impetrar a sua definição pela autoridade legítima mas de a professar com juramento. O Claustro Pleno resolveu - por 34 votos dos 36 presentes - "que vistas e consideradas bem as rasões e grandes fundamentos que se apontaram não avia porque alterar o juramento que nesta universidade se fas e profisão de fee nas ocaciões que o statuto manda". Deste parecer foram também alguns dos professores signatários da petição franciscana, os quais "se retrataram depois que ouviram as resoens e fundamentos que se consideraram. ${ }^{13 .}$ O corpo dos lentes remetia-se ao essencial, o que, numa súmula de verdades fundamentais, jurava, cada ano, antes de se iniciarem os trabalhos escolares, não vendo a conveniência de adoptar uniformemente uma doutrina que, pese embora o favor da autoridade eclesiástica ${ }^{35}$, não fora até ao momento dogmaticamente definida e que poderia, por isso, gerar ainda controvérsia.

Fr. Fernando da Soledade, Historia Serafica Chronologica da Ordem de S. Francisco na Provincia de Portugal, V Part., Liv. IV. Cap. III, pp. 619-620.

A presença de franciscanos no corpo docente da faculdade de Teologia de Coimbra (pese embora o facto de diversas observâncias desta ordem religiosa terem aí os seus colégios) é excepcional e diz respeito apenas a dois professorados breves na cadeira de Durando iniciados em 1547 e 1566. Tal ficará a dever-se à exigência da obtenção do grau de doutor para o exercício professoral, cerimónia dispendiosa e ostentatória que não se coadunava com o espírito de pobreza que professavam. A docência, ao longo do período que decorre entre 1537 e 1771 foi exercida, para além de alguns poucos seculares, por Eremitas de S. Agostinho (22 lentes ou condutários) Cistercienses (17), Dominicanos (15), Beneditinos (15), Jerónimos (14), Lóios (6), Trinitários (6), Carmelitas (6), da Ordem Militar de Cristo (5), Jesuítas (2) e Crúzios (1) (Fernando Taveira da Fonseca, "A Teologia", in História da Universidade em Portugal, vol. I, tomo II. p. 785).

António de Vasconcelos, O mysterio da Immaculada Conceição, p. 79, nota 45. Os outros dois votos foram de parecer que se ouvissem primeiro as razões dos franciscanos, o que foi rejeitado nesta reunião, refere o secretário "por parecer escusado e a ordem de sua magestade nam dar lugar a isso". É visível, quer pela quase unanimidade da resolução tomada, quer pela rejeição do parecer deste dois vogais, que estava em jogo sobretudo a recusa a uma ingerência considerada espúria (a dos franciscanos), embora veiculada através de uma ordem régia.

As últimas intervenções do magistério eclesiástico iam no sentido da defesa da tese imaculista. Por um decreto de 31 de Agosto de 1637, Paulo V autorizava a doutrina da Imaculada Conceição e proibia a exposição ou defesa pública da tese contrária; em 24 de Maio de 1622, Gregório XV reforçava esta proibição, ordenando que, quer em público, quer em particular, de viva voz ou por escrito se não defendesse a doutrina anti-imaculista (António de Vasconcelos, O mysterio da Immaculada Conceição, p. 32). 
As razões e fundamentos constariam de duas exposições - uma do Reitor, outra dos lentes, cada uma formada de nove pontos - enviadas a D. João IV, "as quais [...] mandou El Rey aos nossos Padres [os franciscanos] para que lhes respondessem, e o Provincial commetteo esta diligencia ao Padre Frey Manoel da Esperança, que a todas deu satisfação em hum tratado, do qual nesta memoria lançaremos huma breve summa", diz Fr. Fernando da Soledade. ${ }^{36}$ É através desta relação que temos notícia indirecta da argumentação do Reitor e dos lentes: em uma e outra eram invocadas razões de oportunidade, de competência jurisdicional para definir verdades ou impor juramentos em matéria de religião, e se notava não ser nem urgente nem necessário tornar obrigatória uma opinião considerada piedosa e, já de si, tão geralmente aceite; em ambas também, se referia a existência de uma corrente de opinião que, embora silenciada pelos decretos pontifícios, poderia ser seguida em consciência. O Reitor explicita mesmo que "os religiosos de N. Padre São Domingos não quererião jurar, e que por este modo ficarião impossibilitados para se graduarem." Os lentes, indirectamente a eles também se referiam, quando assinalavam a existência na faculdade de duas cadeiras em que se lia Santo Tomás, "autor da opinião contraria e que seguindo-se a doutrina deste Santo era grande inconveniente jurar o contrario delia"; e não se coibiam de afirmar que "o principio dos Padres Franciscanos neste juramento era só competencia literal", o que equivalia a dizer que, a coberto de um zelo piedoso, os movia apenas o desejo de fazerem vingar a opinião da sua própria escola, confrontando a universidade e os seus professores, o que não seria de todo inexacto ${ }^{37}$.

D. João IV acabará por enviar ao Reitor, por carta de 17 de Janeiro de 1646, a fórmula do juramento que se fizera em Salamanca no ano de 1618. E acrescenta: "Vos encomendo e encarrego muito que tanto que esta receberdes, deis as ordens necessarias para assy se executar muy pontualmente". O Reitor dilatou a execução deste encargo e só a 20 de Julho apresentou a carta em Claustro Pleno. A solene cerimónia do juramento da Conceição celebrou-se a 28 de

${ }^{36}$ Historia Serafica, p. 610.

Ibidem, pp. 620-627. Não pode passar despercebido o tom com que o cronista da História Serafica se refere aos festejos do juramento que, como veremos, acabou por ser feito na Universidade a 28 de Julho de 1646: Os [affectos da alma] que the rendeu a Universidade de Coimbra, e com ella quasi todos os conventos e Collegios, bem declarou que nas replicas mencionadas era mais poderoso o capricho, a que chamamos paixão, do que o sentimento contrario ao privilegio da Sanctissima Virgem: dissemos capricho, porque custaria muyto a tão eruditos sugeytos ver que hum pobre Frade, ou Frades de S. Francisco erão a causa de os obrigarem a tomarjuramento de defender a doutrina que elles professão; mas tambem podião considerar que ordinariamente elege Deos sugeytos humildes para authores de emprezas grandes" (p. 634). 
$\mathrm{Julho}^{38}$. Nela, porém não compareceram os dominicanos nomeadamente Frei Diogo Artur, lente de Prima de Teologia. Informado do que acontecera o monarca dirige-se mais uma vez ao Reitor, estranhando esta ausência. E acrescenta: "mandareis logo chamar estes lentes, e lhes direis da minha parte que Vos dem a razão que tiverão para dispois de eu, com o Reyno junto em Cortes jurar defender a imaculada concepção da Senhora, e a tomar por padroeira destes Reynos, e mandar fazer o mesmo a essa Vniverçidade á semelhança do que se tem feyto na mayor parte das da christandade, mandando primeiro ver, e considerar esta materia com a ponderação que ella pedia, se apartarem do commum do Reyno, e do commum dessa Vniverçidade, em materia tanto do serviço de Deos e meu e como tal mandada fazer por mym com particular recomendação" ${ }^{\prime 39}$.

É exemplar este texto a mais do que um título: a atitude dos dominicanos é considerada como de auto-marginalização (apartaram-se do "commum do Reino" e do "commum da universidade") inesperada e incompreensível ("que vos dem a razão"); dissidentes, são também desobedientes e rebeldes, ao afastarem-se do exemplo régio ("dispois de eu, com o Reyno em Cortes, jurar") e ao não atenderem à expressa vontade do monarca, para mais, fundamentada - como ele próprio afirma - numa séria ponderação, consentânea com a relevância da matéria em questão. É evidente que, independentemente do seu conteúdo específico, o juramento era aqui encarado pelo rei como um acto de conformidade política, no qual se conjugavam o serviço de Deus e o seu próprio.

Fora mal servido D. João IV, assim o entendia ele: e se, ao fazer o seu próprio juramento, em Lisboa, em domingo de Ramos e festa da Anunciação (25 de Março de 1646), cominava com a desnaturalização de seus Reinos todos o que sentissem o contrario da pureza e graça em que a Senhora foi concebida e lançava a maldição a qualquer dos seus descendentes ${ }^{40}$, podemos entender que tenha punido quem deste modo divergia da sua vontade e do seu sentir e. por essa via, punha em causa a indispensável coesão do corpo político.

4. A sequência desta narrativa pode entender-se a partir da reacção dos dominicanos. É por ela que ficamos a saber que D. João IV ameaçava excluir do professorado de Coimbra os lentes da ordem de S. Domingos se estes não

Desta cerimónia nos dá um relato pomenorizado António de Vasconcelos, O mysterio Immaculada Conceição, pp. 41-46 e documentos das notas 51 a 53 (pp. 81-85).

${ }^{39}$ António de Vasconcelos, O mysterio da Immaculada Conceição, doc. da nota 55, pp-86. A carta é de 13 de Agosto de 1646.

40 Historia Serafica, p. 630. 
fizessem o juramento da Conceição: "V. Magestade (Senhor) movido da muita piedade e devação a Conceição da Virgem Sanctissima Nossa Senhora se resolveo a obrigar aos Lentes da Ordem de São Domingos na Universidade de Coimbra com pena de perderem suas cadeiras, a tomar o juramento de ensinar e defender a ditta opinião"

Não é de somenos importância que a defesa da posição dominicana seja assinada não por algum dos doutores teólogos do Colégio de Santo Tomás de Coimbra mas precisamente por Frei Domingos do Rosário, numa tentativa, sem dúvida, de aproveitar o seu valimento na Corte $^{42}$ e claramente indicando que a resolução régia afectava não apenas o titular da cadeira de Prima de Teologia mas todo o corpo dos seus irmãos em religião que com ele se solidarizavam.

O "papel" de Frei Domingos é um escrito claramente político: afastando-se explicitamente da questão doutrinal ao afirmar que não faz tenção "de directa nem indirectamente fallar na verdade nem averiguação da ditta sentença" [da Imaculada Conceição], faz assentar o seu discurso em questões de jurisdição e em razões de conveniência do Estado e da universidade. Escreve com a desenvoltura do homem que conhece a Corte, habituado à lógica "mundana" da influência e do poder e ao qual a sua posição permite falar sem grandes rodeios.

É o que pode verificar-se logo no enunciado do primeiro argumento: "A razão porque não pode $\mathrm{V}$. Magestade [obrigar os lentes de dominicanos ao juramento] he por ser materia dogmatica em que os principes seculares não tem jurisdição nem podem sem peccar mortalmente usurpar jurisdição spiritual nem adiantarse à Igreja em materia de doutrina senão esperar delia a declaração dos pontos duvidosos. ${ }^{43}$ Nada menos que uma usurpação do poder espiritual,

Bilioteca da Ajuda (B.A>50-V-32, doc. 1.

12 Frei Domingos do Rosário era de origem irlandesa (nascera em 1595 no condado de Kerry e o seu nome no século era Daniel 0'Daly) provavelmente parente dos condes de Desmond; viera para Espanha, tendo recebido o hábito de S. Domingos, em Lugo. Estudou em Burgos, leccionou em Bordéus e, de regresso à Irlanda, foi proposto para uma cátedra episcopal. Professor no colégio da sua ordem, em Lovaina, foi enviado a Madrid a tratar negócios dela. Foi então que se propôs estabelecer um colégio em Lisboa, o que efectuou em 1634; o favor que grangeou junto da Duquesa de Mântua irá continuar depois de 1640, com os novos soberanos, por quem nutre verdadeira dedicação. D. Luisa de Gusmão confessava-se com ele e favorecia os dominicanos com esmolas; além disso, foi encarregado de negociações e missões diplomáticas, antes e depois da Restauração, sendo as mais importantes as que o levaram a França em 1655 e 1656. Gozou até ao fim da vida o favor real, tendo sido nomeado bispo de Coimbra, em 1661, cargo que não chegou a ocupar por ter falecido em 30 de Junho de 1662 (Edgar Prestage, Frei Domingos do Rosário, diplomata e político (1595-1662), Coimbra, 1926; M. Lopes de Almeida, Uma nota sobre Frei Domingos do Rosário, Coimbra, 1934).

B.A., doc. 1,fl. 470. 
sancionada com a pena moral do pecado; a que se acrescenta a exigência de o monarca se submeter à determinação papal que ordenava não pudessem ser molestados os dominicanos por discutirem entre si a questão ("inter se duntaxat et non inter alios aut cum aliis"). Donde conclui que "qualquer Principe que lhes der castigo ou molestia por não jurar a negativa ${ }^{44}$ não somente se antecipa, senão que directamente encontra os decretos pontifícios [...]". E prossegue:

"E não pode negar-se ser grande vexação e castigo tirarlhes as cadeiras que actualmente possuem e inhabilitalos pera nunca as terem daqui em diante. Nem basta dizer que $V$. Magestade não poem as dittas pennas por sentirem nem dizerem elles entre si o que quiserem, senão que quer $V$. Magestade pôr tal condição em suas cadeiras como protector daquela Universidade. Porque o pôrse tal condição he grande castigo e prejuizo da opinião affirmativa e huma violencia moral pera se não poder seguir, e como poem V. Magestade a ditta pena, poderá pôr todas as outras de desterro, desnaturalização, etc. (que a mesma razão corre). Logo tira V. Magestade a liberdade que a Igreja dá a todo o fiel christão de sentir o que quizer das duas opiniões..."

Usurpação de competências, violência moral consubstanciada na privação da liberdade de consciência, o que vem a significar abuso de poder e tirania; para mais, em um momento particularmente delicado quer internamente ("não convem no estado presente das couzas dispertar discordias, divisões e desgostos"), quer no contexto da política externa ("E mui crivei he (Senhor) que em chegando à noticia da See Apostolica a rezolução que V. Magestdade quer tomar, ir ella à mão, por ser materia commua e de consequencia, e pellos muitos inconvenientes que do contrario se podem seguir à Igreja em outras materias semelhentes, e ainda maiores e mais perigosas, meteremse os Principes seculares em materia de doctrina; [...] e estando as couzas de Portugal como estão em Roma", seria de todo extemporâneo avivar uma polémica "que a não se despertarem agora estas duvidas poucos da gente vulgar saberião aver duvida nem contraria opinião na materia"46.

${ }^{4}$ Nos documentos que vimos analisando, designava-se por "negativa" a opinião que defendia a imaculada conceiçâo (chamada também "pia opinio" ou "opinião piedosa"); a contrária era referida como a "afirmativa". Esta nomenclatura não se terá mantido, contudo, inalterável. Numa exposição dos lentes de Coimbra de c.1698 acerca deste mesmo assunto, utilizam-se estes qualificativos exactamente em sentido inverso.

${ }^{45}$ B.A., doc. $1, \mathrm{fl} .470 \mathrm{v}$.

${ }^{4}$ B.A., doc. 1, fl. 471. 
Esta linha de raciocínio conduz ao ponto seguinte, no qual o autor dominicano explana, com alguma auto-complacência, o poder de influência de que a sua Ordem goza nos diversos estados da Europa, o que poderá redundar em que, "por esta via, pode grangear V. Magestade muitos desaffeiçoados": desde que se fundara tivera sempre "grandes sujeitos na Igreja de Deus"; costumava dispor, em Roma, de "tres ou quatro Cardeaes quando as mais religiões não tem nenhum"; "nos Conselhos dos Principes Catholicos entrão sempre dous ou tres Capellos juntos da ditta Religião [...], muito cavida com todos os Principes da Christandade e nobreza delia sem ser nada entremetida nem ambicioza". E acrescenta, ainda em Roma, o "magisterio do Sacro Palacio perpetuo que he o mais grave posto de letras que ha na Igreja", os numerosos arcebispos e bispos que na corte pontifícia "sempre serão bem ouvidos [...]; "em França, o cardeal Maserino, hum seu irmão arcebispo [...] e o mesmo nos mais Reynos da Christandade". Escandalizar todos estes "devotos de Sancto Tomas e sua Religião" seria grave erro político e quem aconselhava o monarca "em não reparar em escandalizarlhes", ou era inconsciente ou não deveria ser "mui inteiro ministro". ${ }^{47}$

O maior destaque, contudo, vai para um terceiro considerando: privar os dominicanos das suas cátedras na universidade seria desterrar dela "a mais segura doutrina que ha na Igreja depois da Canonica". E apoia esta afirmação numa série de argumentos: a convocação da autoridade de diversos pontífices que haviam recomendado seguir-se essa doutrina; a reafirmação da exclusiva competência daqueles em matéria de fé ("pasce oves meas, foi dito a São Pedro e não aos principes seculares que tal jurisdição não tem"); a invectiva contra a temeridade de alguns pregadores que se atreviam a afirmar "que não escreveo bem Sancto Thomas, senão com muitos erros" (sugerindo que, perante tal "blasfémia", deveria D. João IV "mandar recado à inquisição e ordinário [...] que averiguem semelhantes excessos"); o exemplo dos outros príncipes católicos (que "pera segurar suas Universidade e perpetuar nellas a doctrina de Sancto Thomas dão à Ordem de São Domingos de propriedade pera sempre as cadeiras de Prima e Vespora", precisamente pelo motivo de "estarem seus lentes atados à doctrina de Sancto Thomas sem terem licença pera se afastarem delia"); a declaração de que "todos os Reynos da Christandade onde está bem recebida e entaboada a doctrina da Sancto Thomas se conservão sem heresia publica e em todos os Reynos onde não está aplaudida entra sua mistura de herezias". 
Tudo converge, afinal, para as duas conclusões a que pretende chegar o defensor dos dominicanos: a primeira, que, tendo servido a Ordem de S. Domingos por tantos anos a universidade (pelo que lhe seria legítimo poder "esperar grandes premios"), não deixava de "parecer rigor verse desestimada e lançada fora afrontozamente da ditta Universidade sem nunca aver commetido a menor culpa contra V. Magestade mais que seguir a seu Mestre [...] e por uma opinião que a Igreja dá por provavel"; em segundo lugar, que o seguirem - sem exclusão de proposição alguma - a doutrina de Santo Tomás (que afirma corroborada por numerosos outros doutores) o faziam "por huma conveniencia politica e razão de estado comua de toda a Igreja (que muitos seculares não sabem)", ou seja, que, em caso de abrir-se alguma brecha a propósito de uma matéria particular ("confeçar toda a Igreja junta que ella em mais de mil annos e todos os ditos Sanctos Padres iuntos errarão neste ponto"), "não quiseram os inimigos da fee mayor gloria nem triumpho", podendo daí inferir "a cada passo que tambem poderião errar em qualquer outro." ${ }^{18}$

À síntese da exposição ("não irrite V. Magestade a See Appostolica nem granjee desafeiçoados nos outros reynos, nem desterre de suas Universidades doctrina tão solida") junta Frei Domingos do Rosário a súplica de que o monarca "seja servido tomar madura consideração sobre os ditos inconvenientes, não se aconselhando com gente apaixonada na materia". Mas, provavelmente pouco convencido da eficácia da sua argumentação, acaba por impetrar que "ao menos se sirva V. Magestade de dar mais tempo para esperar resposta do seu Geral" que tardava, não só por ele se não encontrar em Roma, "como pella falta de embarcações ha tantos tempos". E conclui: "a Religião ainda que quisera, não pode jurar sem relaxação do primeiro juramento pena de peccar mortalmente ${ }^{49}$

ss Ibidem, fl. 472-472v.

49 Este argumento moral que, na exposição de Frei Domingos do Rosário, aparece apenas na conclusão, torna-se central na exposição que, em 1651 (no momento em que a cadeira de Prima de Teologia está de novo vaga pela morte do beneditino Frei Leão de Santo Tomás) os dominicanos, pelo seu procurador geral, Frei Tomás da Cruz, utilizam numa petição que fazem para que ela seja restituída a Frei Diogo Artur; protestando-se "os mais obrigados c beneficiados de Sua Magestade soberana", declaram, contudo, que "não poderão no particular deste juramento fazer o que se lhes representava da parte de V. Magestade a cujo serviço e [palavra ilegível no documento] antepoem a propria consciencia, com a qual não podia nem pode ajustar-se o tal juramento por expresso contra repetidas e apertadas Leys de sua Religião, às quais estão obrigados pello voto da obediencia que debaixo de graves penas mandão que todos os religiozos da dita. tenhão, defendão tudo o que tem, e ensina o Angelico Doutor S. Thomas [...] cuja he expressa a doutrina contraria na sobredita questam" (MCO, UC, maço 60). 
ao que V. Magestade não lhes pode obrigar, nem tam pouco deixar de ouvir em tribunais de justiça o seu Geral como parte que he na cauza." ${ }^{\text {50 }}$

Do "papel" de Frei Domingos do Rosário, deu o monarca conhecimento aos franciscanos, os quais elaboraram uma réplica; o dominicano respondeu com uma tréplica, muito mais extensa e prolixa que a exposição original. Não cabe aqui e agora o exame destes textos, pena de nos alongarmos e de nos repetirmos desnecessariamente. Não pode, contudo, deixar de ser assinalado o antagonismo entre as duas partes, o qual ultrapassa largamente a dimensão da argumentação teológica para se situar nos terrenos da controvérsia entre facções - em termos que, muitas vezes, não primam pela elegância - ambas desejosas de manterem uma posição de influência, ambas querendo fazer valer os próprios méritos.

5. D. João IV irá cumprir a ameaça feita aos dominicanos, privando-os da única cadeira - a de Prima de Teologia, a mais importante da faculdade e da universidade - que então regia Frei Diogo Artur: só o fará contudo em 1648. $\mathrm{O}$ exame das folhas de ordenados permite-nos verificar que, até à segunda terça de 1646-47, o lente dominicano recebe e assina pessoalmente. O vencimento da terceira terça desse ano escolar já é recebido apenas em 16 de Fevereiro de 1649 por um seu procurador, Frei Diogo Pessoa ${ }^{51}$. Na primeira terça de 1647-48, Frei Leão de Santo Tomás (com a titularidade de lente de Véspera igualado a Prima) é pago por substituir as lições desta última cadeira até ao dia 15 de Fevereiro; na terça seguinte já recebe como lente de Prima. ${ }^{52}$

A provisão que concede a cadeira de Prima a Frei Leão de Santo Tomás é de 9 de Março de $1648^{53}$ : ela constitui, depois da carta endereçada ao Reitor Manuel de Saldanha em 13 de Agosto de $1646^{54}$, a referência principal pela qual se pode afirmar que, efectivamente, se tratou de uma exclusão, e não de uma suspensão ou de uma moratória - para além da que já fora, na prática, concedida entre 1646 e 1648 - até que o professor dominicano se resolvesse a jurar a Conceição. Os termos utilizados - "houve por bem por iustas considerações do serviço de Deus e meo mandar declarar por vaga a cadeira de Prima de Theologia" - excluem aquelas duas últimas hipóteses: de facto tratava-se de uma vacatura, ainda em vida do proprietário e sem que este tivesse jubilado ou

Ibidem, fl. 473.

A.U.C., Folhas de ordenados, 1642-1649 (cadernos de 1646-47, fl. inum.).

Ibidem, cadernos de 1647-48, $1^{\text {a }}$ terça, fl. lv.; $2^{a}$ terça, fl. 1v.

A.U.C., Registo de Provisões, tomo 3, fl. 50v.

${ }^{s 4}$ Vide nota 39. 
tivesse sido aposentado ${ }^{55}$; e a imediata concessão dela ao beneditino Frei Leão de Santo Tomás irá criar um direito que tornaria injusta, ou, pelo menos, problemática, a restituição aos dominicanos: estes tentarão reiteradamente esse regresso, ao longo, pelo menos, de toda a segunda metade do século XVII, nas ocasiões em que a cadeira estava ou se previa viria a estar vaga. Sempre de modo infrutífero: no conjunto de forças em presença introduzira-se uma outra, a do corpo dos lentes da universidade (nomeadamente os de Teologia) que sempre se opuseram às pretensões dos dominicanos. O exame dos documentos produzidos nessas circunstâncias pelos diversos intervenientes envolvidos ultrapassa os intentos deste trabalho mas é elucidativo acerca do contraste dos interesses em presença e dos modos de os fazer prevalecer. ${ }^{56}$

Reparemos que na origem desta oposição dos lentes de Teologia não estaria - nem mesmo originalmente - a divergência doutrinal, mas porventura a situação de excepção de que os religiosos de S. Domingos gozavam: como esperar que os professores da universidade - que se submetiam a concurso para o acesso às cadeiras, que, regra geral, começavam pelas de menor graduação e faziam um mais ou menos longo mas sempre difícil percurso ascensional, degrau a degrau, até atingirem o topo (precisamente a cadeira de Prima) - aceitassem de bom grado que outros, ultrapassando todos estes procedimentos, os precedessem, bastando-lhes a indigitação do seu superior? De facto, o que os dominicanos solicitam sempre é que a cadeira seja restituída à sua Ordem, quer dizer que se retome a prática de ser nela empossado e de a reger aquele dos seus membros que eles indicassem.

Os provimentos das cadeiras não eram nem ad tempus, nem ad nutum. Os professores poderiam ser promovidos de uma cadeira a outra, e a jubilação, depois de vinte anos de leitura, embora representasse o termo das actividades propriamente lectivas, não implicava a cessação de outras (presidir actos, apadrinhar, fazer parte de conselhos e juntas...); pelo contrário, representava um acréscimo de dignidade e era acompanhada da respectiva remuneração (dois terços do ordenado). Nenhuma destas circunstâncias se verifica em Frei Diogo Artur. Nem também a de aposentação, mais rara, menos honrosa e devendo-se, as mais das vezes, a incapacidade física, que privava o professor de toda a actividade académica embora lhe conservando a totalidade do seu ordenado.

${ }^{56}$ Já vimos que, em 1651, o procurador geral dos dominicanos solicitou a "restituição" da cadeira de Prima para Frei Diogo Artur, então ainda vivo; pretensão semelhante irá ser reiterada pelo menos em 1685-86, em 1693 e em 1697-98. Em todas estas circunstâncias, os lentes de Teologia se opõem: em 1697-98 produzem um extenso documento - sob a forma de alegação jurídica - em que rebatem ponto por ponto os argumentos dos dominicanos, pondo sobretudo em causa a validade da doação da cadeira que estes alegavam ter-lhe sido feita em 1615 (^4-U.C., Contestação dos professores desta faculdade, dirigida a El-Rei sobre um requerimento dos religiosos de S. Domingos acerca da cadeira de Prima; outros documentos de teor semelhante, referentes às datas indicadas, em MCO.UC, maço 60). 
Nunca o conseguiram: o elenco dos professores de Teologia até à reforma de 1772 não mais os incluirás7 ${ }^{57}$ com uma excepção apenas, a de Frei Valério de Moura. Trata-se, porém, uma excepção significativa: em 23 de Junho de 1698 é-lhe passada, a seu pedido e "para justos requerimentos da sua Religião", uma certidão de como estava incorporado na universidade, tendo nela "tomado o grao de Bacharel e feito todos os actos grandes athe exame privado inclusive". Por ela ficamos a saber que ele se incorporara até Ordinária Magna, por provisão de 12 de Março do mesmo ano, tendo o secretário lançado o termo em oito de Abril: "e no dito dia mez e anno, na Salla dos actos da dita Universidade fez solemnente o juramento da Conceyção de Nossa Senhora em vox alta e inteligivel que eu Secretario lhe dei na forma dos Estatutos". Prossegue a certidão enunciando os restantes exames a que se submetera com êxito e também o exame privado no qual fora aprovado nemine discrepante e sem penitência. E acrescenta: "E em cinco deste dito mez [Junho] em o Real Convento de Santa Cruz e capitulo de S. Theotonio fez o juramento da Conceição de Nossa Senhora que eu Secretario lhe dei na forma sobredita e recebeo o grao de Licenciado em Theologia" tendo-lhe o vigário de Santa Cruz, vice-cancelário da universidade, dado licença "para tomar o grao de Doutor todas as vezes que quisesse" ${ }^{158}$.

Quebrara-se a resistência frades de S. Domingos - notemos que a certidão é pedida por Frei Valério de Moura "para justos requerimentos" da sua religião - pela submissão formal de um dos seus membros à determinação de D. João IV, agora incorporada nos Estatutos da universidade. .9 Mas não apenas por esta via: o religioso dominicano irá iniciar a sua carreira académica de modo normal, como condutário - e, portanto, sem a titularidade de qualquer cadeira - embora, como a muitos outros condutários, lhe tenham sido concedidos os privilégios de lente. Não fará uma carreira longa e não ultrapassará a sua condição inicial, tendo apenas obtido a igualação (e não a propriedade) à cadeira de Escritura Pequena em 1718. Esta circunstância - de ter que percorrer a via académica começando do fundo - terá porventura desmotivado a religião de S. Domingos de continuar a propor membros seus para iniciarem uma carreira na universidade de Coimbra.

Deve notar-se que, antes da sua exclusão, eles ocuparam não apenas a cadeira de Prima mas outras, nomeadamente as de Escritura e de Véspera: na altura dos acontecimentos que narrámos é que havia um só lente, o de Prima, Frei Diogo Artur. A privação estendeu-se a todas as cadeiras.

${ }^{58} \mathrm{MCO}, \mathrm{UC}$, maço 60.

s Na edição de 1654, liv. IV, tít.XIV, pp. 298-299, na qual se narra brevemente a origem do juramento e se reproduz a fórmula que veio finalmente a ser adoptada. 
6. Ao referir que a exclusão dos dominicanos das cátedras universitárias de Coimbra foi uma questão política, tive em mente acentuar que, fosse qual fosse a divergência doutrinal que lhe esteve subjacente, o que releva de todo este episódio é o confronto da vontade do monarca com a de uma corporação que funda a sua resistência no que pensa ser o seu direito, alicerçado na convicção de uma mercê régia que não poderia ser derrogada sem causa justa (para mais confirmada por uma posse longa, se bem que não ininterrupta), e de uma liberdade de consciência facultada pela máxima autoridade eclesiástica (a única que poderia definir matéria dogmática), a qual se julgava posta em causa por uma exigência extemporânea do poder civil, configurando uma usurpação jurisdicional.

Do outro lado, naturalmente, um entendimento diferente: o de que a concessão da propriedade de uma cátedra universitária - no caso vertente, a mais importante de todas em dignidade - era matéria que relevava da graça e não da justiça, o que permitia ao monarca, a partir de qualquer momento, estipular as condições dessa mesma concessão ou da continuidade da mercê. Porque era ao rei, na sua qualidade jurada de protector, que pertencia, em primeira mão, a jurisdição universitária.

Os juramentos, de diversos tipos, vinculavam a generalidade da população da universidade - professores, estudantes, oficiais, ministros de justiça; o mais relevante, era, sem dúvida aquele que, anualmente, no início dos trabalhos lectivos, os lentes faziam - o "juramento da profissão de fé, segundo a bulia do papa Pio IV"60 - o qual juntava às declarações do "credo", comum a todos os católicos, um conjunto de proposições consideradas essenciais ao núcleo central da ortodoxia. No seu conjunto, tratava-se de instrumentos destinados a assegurar a conformidade, a solidariedade institucional e a coesão derivada do respeito à autoridade. Mas transcendem o círculo restrito da universidade: porque esta é, pela sua estreita ligação ao poder eclesiástico e ao poder civil, um órgão essencial do corpo político - a matriz geradora do modelo de pensamento, de vida e de actuação política que lhe devia dar forma.

Se atentarmos na conjuntura em que foi imposto o juramento da Conceição - de um poder recentemente adquirido e ainda mal consolidado - é evidente que a marginalização face ao comum do reino e ao comum da universidade, protagonizada pelos dominicanos, não poderia entender-se senão como rebeldia intolerável. 